\title{
Food markets visitors: a typology proposal
}

Phd. Montserrat Crespi Vallbona. Faculty of Economics and Business, Economy and Business Organization Department, University of Barcelona, Spain. mcrespi@ub.edu

Phd. Darko Dimitrovski. Faculty of Hotel Management and Tourism, University of Kragujevac, Serbia. darko.dimitrovski@kg.ac.rs

\begin{abstract}
:
Purpose

Focusing on food markets popularity among tourists, the purpose of this article is to differentiate clusters of tourists based on their behavior during their visit of these food halls.

Design/methodology/approach

Factor-cluster analysis is the segmentation method used to identify food markets groupings related to their motivations, while ANOVA was performed to determine differences between clusters when it comes to perceived authenticity, satisfaction and revisit intention. La Boqueria in Barcelona (Spain) is the paradigmatic food market used to conduct 196 survey respondents based on factor importance.
\end{abstract}

\section{Findings}

Two homogenous clusters were identified and labelled as Apathetic-market Visitors and Food-market Lovers.

\section{Practical implications}

Segmentation proposal provides insights to be taken into account for future Destination Management Organization's policies, related to promotional activities and destination branding development. They could create effective tailor-made promotional campaigns and adequate business strategies to further attract more food lovers markets, without removing apathetic-market visitors.

Originality/value

Fill the gap in the existing knowledge on the tourism interest of local markets in destinations and identify through factor-cluster analysis.

Keywords: food-markets, food-market lovers, apathetic-market visitors, satisfaction, tourist icon, Barcelona

Article classification: research paper

\section{INTRODUCTION}

Gastronomic tourism is the current trend and the volume of gastro-travellers increase day by day. It is defined as that trip that focuses its interest on exploring and enjoying meals and beverages, to experience local cultures. Therefore it is a kind of tourism that connects travel, leisure, and food (Smith \& Xiao, 2008) and provides travellers with memorable experiences (Hashimoto \& Telfer, 2006; Okumus et al., 2013). 
The food market serves as the commercial and social centre of communities, reflecting local culture and traditions of the people. They are one example of settings where people carry out their daily activities. In consequence, tourists find in markets reflections of the cultures they want discover and enjoy during their holiday period (Hjalager and Richards, 2002; OECD, Richards, 2012). Food markets are exceptional spaces filled with history and culture of a territory, tastes and eating habits of the inhabitants of a destination. They are part of the rich heritage of a city, and become a great and attractive resource for visitors (Crespi-Vallbona \& Domínguez-Pérez, 2015, p. 129). Therefore, elements of culture and heritage belong to the food experience, including shopping (farmer's markets and food markets), and cultural events featuring food and other local traditions.

Segmentation of food tourists is not so common in food tourism literature. Kim et al. (2015) and Kim et al. (2014) used involvement as a segmentation method to divide food festival visitors, but no research has been conducted using the involvement construct among food markets attendees, and thus, this research attempts to fill this gap. The strong difference between potential segments of food market tourists is consequence of motivations favouring their involvements.

\section{LITERATURE REVIEW}

Previous literature attempts to understand motivators for attendance, levels of satisfaction and revisit intention at food festivals (Kim, Kim et al., 2010; Kim, Suh, \& Eves, 2010; Lee et al., 2010). These researches focus the attention on perceived value as a key aspect to predict satisfaction and intention to revisit (Zeithaml, 1988; Bolton \& Drew, 1991; Chang \& Wildt, 1994; Kim, Eves, \& Scarles, 2009; Kim, Kim, Goh, \& Antun, 2011). Other enquiry notes that food is often an integral part of the tourism experience (Kim, Kim, and Goh, 2011), and food festivals provide not only an eating experience, they also offer a complete tourism experience (Yuan, Cai, Morrison, \& Linton, 2005). Thus, experiencing a specific region's local cuisine or a special wine or food type has been found as a major travel motivation for many visitors (Park, Reisinger, \& Kang, 2008). Additionally, the association of food with health concern, the significance of locally made items or locally grown specialties of the region are frequently highlighted at food festivals (Everett \& Aitchison, 2007; Lee \& Arcodia, 2011). And lastly, it is also shown the socialization, interaction with locals, and hospitality of inhabitants as other explanatory variables of tourism motivators.

Accordingly to the aforementioned aspects taken into account in these several researches related to food tourism, it is proposed specific variables to explain the interest of gastrotravellers in visiting food markets wherever they go. These different variables are sensory

appeal, health concern, local food experience, interaction with local producers and vendors, and perceived authenticity.

Several studies (Kim et al., 2009; Steptoe et al., 1995; Kim and Eves, 2012; Hjalager \& Richards, 2002) demonstrate that sensory appeal has a lot to do in visiting food halls. All these scholars argue the importance of food looks, smell and taste.

Normally, vendors take special attention to the preservation, presentation and decoration of their stalls. They use to spend time to show their goods in order, variety of colours, healthy aspect, etc. to attract buyers. Gastro-travellers enjoy wander up and down different alleys of the food market, looking around and discovering the great colours explosion, shapes and 
smells. It is also plenty of social networks where people share their pictures and food markets have a special attention. The effects of culture determine which foods are acceptable in terms of their sensory properties (Prescott et al., 2002). So depending on their cultural values and beliefs, tourists will choose one food or another based on their sensory perception.

Since the study of Steptoe et al. (1995) health concern is another decisive attribute of food markets visit. It is proved that tasting local food keeps people healthy (Swenson, 2009). Local food contains a lot of fresh ingredients produced in a local area and also use to be more nutritious than other kind of food. Therefore, gastro-travellers use to visit these healthy spaces.

Good quality of things, variety of farmed products and nutritious worth are, among others, some of the main interests to choice and buy in food markets (Steptoe et al., 1995). "Quality" is a term often associated with local, farmed and organic food. It is known that local and organic food has been identified as a means to increase trust in the food that people eat. In consequence, visitors tend to provide local products and food miles from years (Zanoli \& Naspetti, 2002; Albisu et al., 2011), because taste and freshness have always been considered as relevant attributes of local products and food miles and also have been linked to healthy life. As Lang et al (2014, p. 1817) argue "local foods trend is more than just produce food miles to consumers" and evolves a redefinition of food quality because consumers look for a more personal connection and involvement with local owned business; food miles and typical products to the region, and prioritize small-scale producer.

Local food experience has been analysed by Kim and Eves (2012). The original open-air place or the historic building which houses the food market and the tasting experience of local food are key elements to take the decision to visit these halls. Local food involvement influences tourists to visit specific gastronomic places according to the research results of scholars (Kim et al. 2010; Turner and Hope, 2014; Organ et al., 2015).

Chang et al. (2010) stated that local food experience implies locally produced or grown food and local specialty food that has a local identity. Eating local food, in authentic local environment, is an essential part of the tourism experience (Kim et al., 2009), since it serves as both a cultural and an entertainment activity. It plays an important role in introducing tourist to flavours and different traditions at destinations (Kivela \& Crotts, 2006). Tasting local food is an opportunity to encounter various facets of the local culture, to have an authentic travel experience (Chang et al., 2010). According the exciting experience, it is worth highlighting that cities have become "experimental places" (Barrado, 2010), where the local experience is needed. This involves another new paradigm: a change from going somewhere to see something to going somewhere to do something (Crespi-Vallbona \& DomínguezPérez, 2015).

Interaction with local producers and vendors is one important aspect that tourists take into account to decide visiting food halls. According to Organ et al. (2015) food markets visitors are interested in learning more about local and local food products because in their daily life they use to buy food from local markets and farmers' markets as much as possible and also buy food that is produced locally.

Open-air and covered markets are both seen as places for exchange, sociability and a way into local culture. And it is worth to remain that to many tourists, the immersion in the culture of the "other" is a main draw to visit a destination. Mainly, tasting foodstuffs, with 
accompanying explanations, it is an important aspect of the tourist food experience. It entails the discovery and appropriation of a foreign culture, of "the other": the local, the rural, the vendor, the farmer...Exchange, dialogue, discussion, the creation of social links with producers are seen as essential to the tourist food quest. The popularity of local markets is evidence that tourists seek direct links and experiences with producers and vendors (Delfosse, 2011). Therefore, markets are good places for interaction.

The differentiation between tourists is generally based on their demographics and travel behaviour. Food tourists have a specific behaviour when they plan their trip, especially focusing their attention on food. They want access and consume to fresh, quality and locally grown food.

Kim et al. (2009) identified that socio-demographic variables serve as valuable determinants of tourist food consumption. Female and older respondents with higher education level were found to be more concerned about health and have stronger desire to experience local cultures through local food consumption (Kim et al., 2009). Nevertheless, Tse and Crotts (2005) found that tourists' age was negatively correlated with the number and range of their local food consumption.

Behavioural variables were found to be stronger predictors of group membership than demographics (Oh \& Jeong, 1996; Yuksel and Yuksel, 2002a, 2002b; Kim et al., 2015, Sanchez-Cañizares \& Castillo-Canalejo, 2015). Food tourists' differences are already observed in Kim et al. (2010), who explore the differences between first time visitors and repeaters at a food event in US. Length of stay was also found to be important clustering factor in other papers, also researched in food events context (Kim, et al., 2015). Horng et al. (2013) clustered family and quality valued type and work and fashion inclined type of visitors during Macau Food Festival and Taiwan Culinary Exhibition. This leads to the proposition of the following hypothesis:

H1: There are significant differences in clusters based on the Demographics.

H2: There are significant differences in clusters based on the Travel behaviour.

All these variables sensory appeal, health concern, local food experience and interaction with local producers and vendors have a direct relationship with satisfaction and revisit intention (Mason and Paggiaro, 2012). Satisfaction is a necessary component in determining repeat patronage or revisit intention. As Kim et al. (2010) argue many scholars have proved that tourists with a previous experience in travelling increase the intention to travel whenever to those known destinations due to the satisfaction and perceived value are great, important, unique (Sonmez \& Graefe, 1998). They have the tendency to repeat the visit because it is less risky, closer, and familiar and they feel confidence and safer. These assumptions have been settled on business tourists, and Kim et al. (2010) demonstrate that food tourists also are more likely to revisit a destination where they have been before. With this in mind the following hypothesis are proposed:

H3: There are significant differences in clusters based on the Satisfaction.

H4: There are significant differences in clusters based on the Revisit Intention.

But there is another important aspect to take into account when segmenting food market tourists: the perceived authenticity (Robinson and Clifford, 2012; Sims, 2009; Tregear et al., 1998; Brida, et al., 2013). 
By consuming local, traditional or farmed products, the tourist adopts the values associated with local identity codes. They like to taste the authenticity, uniqueness and novelty of the visited destination. The current interest of urban tourists has to do with the participation of real and genuine experiences linked to residents. One of the best ways to be and behave as a local is visiting a food market. This tourist resource let people introduce to the culture, history and local tastes and eating habits of inhabitants of a territory. Indeed, the aspect of "local" is automatically linked to "authentic" which has been a key element for the tourism industry (Taylor, 2001, p. 7). Some researchers (Hu et al., 2013; Mak et al., 2013; Mak et al., 2012; Kim and Eves, 2012; Cohen \& Avieli, 2004; Fields, 2002) have widely analysed the cultural experience in gastronomic tourism trend, related to the perceived authenticity. Given this, it is proposed the following hypothesis:

H5: There are significant differences in clusters based on the Perceived authenticity.

\section{METHODOLOGY}

\section{Data collection}

The study was conducted on a convenience sample of 196 respondents, tourists who visited La Boqueria food market from the beginning of March 2015 until the end of June 2015. The selected tourists to answer the survey were as domestic visitors (Spanish people visiting Barcelona and living out of Catalonia region) and international tourists.

La Boqueria is the most popular and frequently visited market in Barcelona (Spain), but also one of the most famous food markets in the world. It has two hundred and fifty-seven establishments that mix traditional products with delicatessen ones, local and foreign goods. There are a significant number of stalls that target only new customers $(15 \%$ of the total of establishments): fresh juices, fruits cut into pieces, take-away and ready meals, sweets, candies and chocolates, etc., products that tourists can easily consume during their visit. Furthermore, we can find the traditional stalls of meat, fish, fresh fruits and vegetables, and other products of recognized quality (mushrooms, spices, nuts...) and also gourmet ones. This group of establishments represent the $50 \%$ of the total. The rest $35 \%$ combines local and traditional products with tourist ones. In that case, their desks (just using 5\% of the space) display products prepared to take-away and easy to taste for tourists, but the rest of the stall shows traditional products to residents. The $25 \%$ of total establishments sell their own locally produced products. Wholesalers with food miles and fresh, traditional and international products supply rest of establishments.

It also provides in and take-away facilities, with 13 stalls that prepare and offer meal to eat inside the market (12 bars and snacks, and 1 restaurant) and 6 stalls that offer take-away meal: pizza slices, pasties, crêpes, sandwiches, croquettes, paper cons plenty of Iberian and Serrano ham, etc. The schedule is also expanded (up to 21 hours), from Monday to Saturday. It is necessary to point out that the rest markets of the city do not open on Monday, and close earlier, at 20 hours at night. Furthermore, la Boqueria also plans cooking classes for children and adults, and organizes gastronomic events, for residents and tourists. It is well connected by public transport and also offers parking services.

The IMMB (Municipal Institute of Barcelona Markets) is the public organization who manages all food markets in Barcelona. This organization estimates that La Boqueria has a 
volume of billing of 95-100 million Euros per year, with an average of $€ 400,000$ per establishment, albeit with a lot of variability. The total employees are 3000: 2000 are direct employees, the rest are indirect ones.

Furthermore, La Boqueria has been awarded as the best market in the world in the International Congress of Public Markets in Washington (USA, 2006). It is also classified as a sustainable market, due to its shared and compatible interest with local public as well as foreign visitors. So despite taking care of residents, providing them their necessary goods, this market is also a tourist attraction and therefore promoted in tourist guides. This balance, this shared interest between tourism and traditional and usual customers, keeps and retains its attractiveness and sustainability (Crespi-Vallbona \& Domínguez-Pérez, 2015).

During La Boqueria visit, tourists were interviewed. Only visitors above 18 years old were presented with the questionnaire consisting of 15 questions divided into four latent variables. Confidentiality and anonymity were secured during survey process. During the survey a purposive convenience sampling method was used in order to obtain information from specific groups. The goal of our research was to segment the tourists who are visiting La Boqueria, based on their food market behaviour. Mainly, the respondents were required to specify their level of agreement with the given statements about their food market behaviour on a seven-point Likert scale (1 - I completely disagree; 7 - I completely agree). On a similar scale, respondents were asked to give their opinion concerning their attitude towards perceived authenticity, and about satisfaction and revisit intention. Finally, the survey was closed with basic demographic and travel behaviour questions.

It is worth noting that before the distribution, the questionnaire was tested in order to check whether the statements are clear enough and in order to avoid ambiguities. This preliminary test included 15 participants and based on the results obtained through their feedback several minor modifications were made to the initial statements that led to the final version of the questionnaire.

Each variable was measured with three or four statements. The items were selected based on food tourism literature review (Kim et al., 2009; Steptoe et al., 1995; Kim and Eves, 2012; Organ et al., 2015). All the statements were initially adapted for the purposes of this study.

\section{Analytical method}

Upon completion of survey, all usable data was put into Statistical Package for Social Sciences (version 20.0) for statistical analysis. Various analyses were conducted, at first, descriptive statistics was performed to obtain the profile of the total sample. Then the factor analysis was conducted in order to identify the attitude dimensions. Hierarchical clustering with Ward's linkage method was used to identify the appropriate number of clusters. K-means cluster analysis was applied in order to classify the samples according to number of clusters identified through the hierarchical clustering procedure. After segmentation was completed, discriminant analysis was utilized to verify cluster membership results. Comparisons between groups based on their demographic and travel patterns were examined through cross-tabs with chi-square test. Finally, one way ANOVA was performed to determine the statistical 
significance of the differences between clusters when it comes to perceived authenticity, satisfaction and revisit intention.

\section{RESULTS}

\section{Basic profile of respondents}

The socio-demographic characteristics of the tourists visiting La Boqueria are presented in Table 1 . The descriptive analysis of the sample shows that there are more female $(53.1 \%)$ than male respondents. The majority of the respondents belong to age groups 25-34 (31.6\%) and $18-24(28.6 \%)$ with at least bachelor degree $(35.2 \%)$. A total of $51.5 \%$ of the participants are single, mostly employed (73\%). In general, food market tourists are younger, single employed woman with bachelor degree. These demographic characteristics are generally similar to results presented in several studies observing food-themed activities (Kim et al, 2014; Kim et al., 2015; Ignatov \& Smith, 2006).

Table 1. Socio demographic characteristics of the sample $(n=196)$

\begin{tabular}{|c|c|}
\hline Gender & Number of respondents (\%) \\
\hline Male & $92(46.9 \%)$ \\
\hline Female & $104(53.1 \%)$ \\
\hline \multicolumn{2}{|l|}{ Age } \\
\hline $18-24$ & $56(28.6 \%)$ \\
\hline $25-34$ & $62(31.6 \%)$ \\
\hline $35-44$ & $41(20.9 \%)$ \\
\hline $45-54$ & $25(12.8 \%)$ \\
\hline $55-64$ & $9(4.6 \%)$ \\
\hline$>65$ & $3(1.5 \%)$ \\
\hline \multicolumn{2}{|l|}{ Education } \\
\hline High school graduate & $34(17.3 \%)$ \\
\hline Associate degree & $51(26.0 \%)$ \\
\hline Bachelor's degree & $69(35.2 \%)$ \\
\hline Master's degree & $42(21.4 \%)$ \\
\hline \multicolumn{2}{|l|}{ Marital status } \\
\hline Married & $85(43.4 \%)$ \\
\hline Single & $101(51.5 \%)$ \\
\hline Other & $10(5.1 \%)$ \\
\hline \multicolumn{2}{|l|}{ Employment } \\
\hline Employed & $143(73.0 \%)$ \\
\hline Unemployed & $47(24.0 \%)$ \\
\hline Retiree & $6(3.0 \%)$ \\
\hline
\end{tabular}

Visitors to La Boqueria market involved in our research are mostly from Great Britain (30), France (28), USA (20), Italy (19), Germany (16) and Netherlands (10), all other nations have less than ten visitors. There are also 17 Spanish visitors, visiting Barcelona and living out of Catalonia region. As majority of the visitors are from European countries and USA, sample is properly consistent to Occidental countries motivations, attitudes and benefits searched, by visiting local food markets, especially in comparation to Asian visitors (Japanese or Chinese).

To understand better tourists visiting food markets, it is important to take into consideration also their travel behaviour. So, the sample consisted of $63.8 \%$ (125) of tourists who visited La Boqueria for first time, while $36.2 \%$ (71) of the respondents are repeaters. Tourists received 
information about La Boqueria primarily through word of mouth propaganda $56.6 \%$ (111), or through the Internet $37.8 \%$ (74). Travel organization is mainly individually $77.6 \%$ (152) or with friends and relatives $52 \%$ (102). Length of stay is usually one week $48.5 \%$ (95), or weekend $31.6 \%$ (62). Main reason of Barcelona visit is diverse, although the survey was conducted at the food market, the percentage of respondents stated that gastronomy is not their main motivation, surprisingly small, just $6.1 \%$ (12). Tourists are coming to Barcelona primarily interested in city sightseeing $26.5 \%$ (52) or cultural experience $24.5 \%$ (48) (Table 2).

Table 2. Travel behaviour $(\mathrm{n}=196)$

\begin{tabular}{|c|c|c|c|}
\hline Type of visit & & Length of Stay & \\
\hline First-time & $63.8 \%(125)$ & One day & $5.6 \%(11)$ \\
\hline Repeat visitors & $36.2 \%(71)$ & Weekend & $31.6 \%(62)$ \\
\hline Information about La Boqueria & & One week & $48.5 \%(95)$ \\
\hline Internet & $37.8 \%(74)$ & More than one week & $14.3 \%(28)$ \\
\hline $\begin{array}{c}\text { Advertisements in magazines or } \\
\text { newspaper }\end{array}$ & $3.6 \%(7)$ & $\begin{array}{c}\text { Main purpose of Barcelona visit } \\
\text { (Primary purpose) }\end{array}$ & \\
\hline Television & $2 \%(4)$ & Food and cuisine & $6.1 \%(12)$ \\
\hline Word of mouth & $56.6 \%(111)$ & Business (Conference) & $2.6 \%(5)$ \\
\hline Holiday Organization Mode & & Visit friend/family & $12.8 \%(25)$ \\
\hline Individually & $77.6 \%(152)$ & Shopping & $5.6 \%(11)$ \\
\hline Package tour & $22.4 \%(44)$ & Sightseeing & $26.5 \%(52)$ \\
\hline Accompanying Person & & Night life & $2 \%(4)$ \\
\hline Travel alone & $15.8 \%(31)$ & Visit historic sites & $9.7 \%(19)$ \\
\hline Spouse & $20.4 \%(40)$ & Cultural experience & $24.5 \%(48)$ \\
\hline Spouse and children & $11.7 \%(23)$ & Other & $10.2 \%(20)$ \\
\hline Friends/relatives & $52 \%(102)$ & & \\
\hline
\end{tabular}

\section{Analysis}

In the first step, factor analysis was applied to segregate 15 food market behavioural items into factors. It is obtained a four-factor solution with eigenvalues higher than 1, accounting $64.892 \%$ of the total variance, using the criteria suggested by Hair et al. (2006). A KaiserMayer-Olkin measure equals 0.848 proving that the distribution of values was adequate for conducting factor analysis. Cronbach's alphas $(\alpha)$ for the four factors range from 0.734 to 0.811. One item was excluded from further analysis as value of Cronbach's alphas $(\alpha)$ is less required than minimum. These results suggest that food market behaviour is diverse, so tourists have a different perception about food market as tourist attraction.

Table 3. Exploratory factor analysis

\begin{tabular}{|c|c|c|c|c|}
\hline Factors & $\begin{array}{c}\text { Factor } \\
\text { Loading }\end{array}$ & Eigenvalue & $\begin{array}{c}\text { \% of } \\
\text { variance } \\
\text { explained }\end{array}$ & $\begin{array}{c}\text { Cronbach } \\
\text { Alpha }\end{array}$ \\
\hline $\begin{array}{c}\text { Factor 1:Interaction with local producers } \\
\text { and vendors }\end{array}$ & & 2.795 & 18.633 & 0.800 \\
\hline Learning more about local producers & 0.812 & & & \\
\hline $\begin{array}{c}\text { I like discussing food products with local } \\
\text { producers }\end{array}$ & 0.788 & & & \\
\hline
\end{tabular}




\begin{tabular}{|c|c|c|c|c|}
\hline $\begin{array}{l}\text { I try to buy food from local markets and } \\
\text { farmers' markets as much as possible }\end{array}$ & 0.750 & & & \\
\hline I like to buy food that is produced locally & 0.575 & & & \\
\hline Factor 2: Sensory appeal & & 2.503 & 16.687 & 0.808 \\
\hline $\begin{array}{l}\text { It is important to me that the food in food } \\
\text { markets looks nice }\end{array}$ & 0.841 & & & \\
\hline $\begin{array}{l}\text { It is important to me that the food in food } \\
\text { markets tastes good }\end{array}$ & 0.807 & & & \\
\hline $\begin{array}{l}\text { It is important to me that the food in food } \\
\text { market smells nice }\end{array}$ & 0.795 & & & \\
\hline Factor 3: Local food experience & & 2.413 & 16.085 & 0.811 \\
\hline $\begin{array}{c}\text { Experience of local food in its original place } \\
\text { makes me excited }\end{array}$ & 0.807 & & & \\
\hline Tasting local food is thrilling to me & 0.740 & & & \\
\hline $\begin{array}{c}\text { When tasting local food I have an expectation } \\
\text { that it is exciting }\end{array}$ & 0.720 & & & \\
\hline Tasting local food makes me feel exhilarated & 0.560 & & & \\
\hline Factor 4: Health concern & & 2.023 & 13.487 & 0.734 \\
\hline Tasting local food keeps me healthy & 0.803 & & & \\
\hline $\begin{array}{l}\text { Local food contains a lot of fresh ingredients } \\
\text { produced in a local area }\end{array}$ & 0.769 & & & \\
\hline Local food is nutritious & 0.721 & & & \\
\hline
\end{tabular}

Notes: Extraction Method: Principal Component Analysis: Rotation Method: Varimax: Only loadings greater than 0.5 are reported; Percent of variance explained is $64.892 \%$; KMO $=0.848>0.5$; Bartlett test of Sphericity:

$$
\mathrm{p}=0.000
$$

Factor 1, interaction with local producers and vendors, has the highest value of variance $(18.633 \%)$, and reliability coefficient of 0.800 (Table 3). This factor incorporates four items, describing attitude towards interaction with local producers in food market. Sensory appeal, factor 2 , includes three items with variance value of $16.687 \%$, explaining the role of smell, look or taste as behavioural antecedents towards food market visitation. Factor 3, local food experience (16.085\%) consists of four items, focusing on excitement with local food experience and taste. Factor 4 (13.487\%), named health concern encompasses the items describing importance of healthy and nutritious local food in food market context. Values of Skewness and Kurtosis are symmetrically distributed around mean, concluding that data was normally distributed. The results indicated that the values of Skewness ranged from -0.777 to -0.278 and from -0.085 to 0.281 for Kurtosis are considered excellent for further analysis.

After factor analysis, a cluster analysis was conducted, based on the factors described above. The four factors separated in factor analysis were used as composite variables in the identification of the clusters. In order to determine the number of clusters, the hierarchical cluster Ward method was conducted indicating two-cluster solution supported by agglomeration coefficient significant increase between steps 194 and 195 (590.691-780.000).

Then hierarchical, non-hierarchical method, k-means cluster analysis was performed using the cluster number from the first step. Two cluster-segmented tourists based on their attitude towards food market visit, into cluster 1 (88) and cluster 2 (114) (Table 4).

Table 4. Food market behaviour

\begin{tabular}{|c|c|c|c|c|}
\hline Factor & Cluster 1 (n=82) & Cluster 2 (n=114) & Total mean & F-value \\
\hline Health concern & 4.64 & 5.74 & 5.28 & 83.662 \\
\hline Sensory appeal & 5.29 & 6.36 & 5.91 & 77.393 \\
\hline Local food experience & 4.52 & 5.80 & 5.27 & 131.403 \\
\hline Interaction with local & 4.11 & 5.27 & 5.02 & 164.623 \\
\hline
\end{tabular}


Next cluster analysis, discriminant analysis was used to check classification validity of the resultant clusters (Hair et al., 2006). The discriminant analysis conducted on all four factors resulted in one canonical discriminant function. A Wilk's lambda test was used to determine the significance of four factors. The results reveal that each of them makes a statistically significant contribution to the discriminant function.

The classification matrix was used to determine the success rate of the discriminant function. Accuracy rate obtained is very high (99.5\%) and 196 grouped cases are regularly classified, with absolute classification result for cluster 2 (Table 5).

Table 5. The evaluation of cluster formation by classification results

\begin{tabular}{|c|c|c|c|}
\hline \multirow{2}{*}{ Cluster case } & \multicolumn{3}{|c|}{ Predicted group membership } \\
\cline { 2 - 4 } & Cluster 1 & Cluster 2 & Total \\
\hline Cluster 1 & $78(95.1 \%)$ & $4(4.9 \%)$ & $82(100 \%)$ \\
\hline Cluster 2 & $0(0.0 \%)$ & $114(100.0 \%)$ & $114(100 \%)$ \\
\hline
\end{tabular}

Note: $99.5 \%$ of original grouped cases correctly classified; $98.0 \%$ of cross-validated grouped cases correctly classified.

As cluster sizes obtained by discriminant analysis vary from the initial cluster results with kmeans cluster analysis by just one respondent, results from the discriminant analysis were saved and used in following analysis

In order to determine the particularities of the identified clusters, each cluster was crosstabulated with external variables (socio demographics and travel behaviour). Variables used within first cross-tabulation included gender, age, education, marital status, and employment. The results of the chi-square tests indicate that there is no statistically significant difference between clusters when it comes to demographics characteristics (Table 6), rejecting hypothesis $\mathrm{H} 1$.

Table 6. Socio demographic characteristics of two clusters of tourists visiting La Boqueria

\begin{tabular}{|c|c|c|c|c|}
\hline Demographics & $\begin{array}{c}\text { Cluster } 1 \\
(\mathrm{n}=\mathbf{8 1})\end{array}$ & $\begin{array}{c}\text { Cluster } 2 \\
(n=114)\end{array}$ & Total & Statistics \\
\hline Gender & & & & $\mathrm{Chi}^{2}=0.750 ; \mathrm{p}=0.386^{\mathrm{ns}}$ \\
\hline Male & 41 & 51 & $92(46.9 \%)$ & \\
\hline Female & 40 & 64 & $104(53.1 \%)$ & \\
\hline Age & & & & $\mathrm{Chi}^{2}=5.316 ; \mathrm{p}=0.379^{\mathrm{ns}}$ \\
\hline $18-24$ & 29 & 27 & $56(28.6 \%)$ & \\
\hline $25-34$ & 24 & 38 & $62(31.6 \%)$ & \\
\hline $35-44$ & 13 & 28 & $41(20.9 \%)$ & \\
\hline $45-54$ & 10 & 15 & $25(12.8 \%)$ & \\
\hline $55-64$ & 3 & 6 & $9(4.6 \%)$ & \\
\hline$>65$ & 2 & 1 & $3(1.5 \%)$ & \\
\hline Education & & & & $\mathrm{Chi}^{2}=4.167 ; \mathrm{p}=0.219^{\mathrm{ns}}$ \\
\hline High school graduate & 9 & 25 & $34(17.3 \%)$ & \\
\hline Associate degree & 24 & 27 & $51(26.0 \%)$ & \\
\hline Bachelor's degree & 31 & 38 & $69(35.2 \%)$ & \\
\hline Master's degree & 17 & 25 & $42(21.4 \%)$ & \\
\hline Marital status & & & & $\mathrm{Chi}^{2}=4.327 ; \mathrm{p}=0.244^{\mathrm{ns}}$ \\
\hline Married & 30 & 55 & $85(43.4 \%)$ & \\
\hline
\end{tabular}




\begin{tabular}{|c|c|c|c|c|}
\hline Single & 46 & 55 & $101(51.5 \%)$ & \\
\hline Other & 5 & 5 & $10(5.1 \%)$ & \\
\hline Employment & & & & $\mathrm{Chi}^{2}=0.188 ; \mathrm{p}=0.910^{\mathrm{ns}}$ \\
\hline Employed & 59 & 84 & $143(73.0 \%)$ & \\
\hline Unemployed & 20 & 27 & $47(24.0 \%)$ & \\
\hline Retiree & 2 & 4 & $6(3.0 \%)$ & \\
\hline \multicolumn{4}{|c|}{ Notes: ${ }^{\mathrm{ns}}$ non-significant }
\end{tabular}

As behavioural variables are stronger predictors of group membership than demographics (Oh \& Jeong, 1996), identified clusters are also cross-tabulated with variables that best describes travel behaviour patterns (type of visit, information about La Boqueria, holiday organization mode, accompanying person, length of stay and main purpose of Barcelona visit). The results of the chi-square tests indicate that there is statistically significant difference between clusters when it comes to travel behaviour (Table 6), supporting hypothesis H2.

The results of the $\chi^{2}$-tests reveal that there is statistically significant difference between the clusters in terms of type of visit, length of stay and main purpose of Barcelona visit, while Information about La Boqueria, holiday organization mode and accompanying person show no statistical significance. Tourists clustered in cluster 2 are first time visitors, while cluster 1 is mostly consisted from repeat visitors. Length of stay for cluster 1 visitors is one week and more, while cluster 2 are mainly weekend tourists. Main purpose for cluster 2 is sightseeing and cultural experience, while cluster 1 visitors are primary visiting Barcelona for friend and family visitation and other motives (Table 7).

Table 7. Travel behaviour of two clusters of tourists visiting La Boqueria

\begin{tabular}{|c|c|c|c|c|}
\hline Travel behaviour & $\begin{array}{c}\text { Cluster } 1 \\
(\mathrm{n}=81)\end{array}$ & $\begin{array}{c}\text { Cluster } 2 \\
(n=114)\end{array}$ & Total & Statistics \\
\hline Type of visit & & & & $\mathrm{Chi}^{2}=2.916 ; \mathrm{p}<0.1 *$ \\
\hline First-time & 46 & 79 & $63.8 \%(125)$ & \\
\hline Repeat visitors & 35 & 36 & $36.2 \%(71)$ & \\
\hline Information about La Boqueria & & & & $\mathrm{Chi}^{2}=2.348 ; \mathrm{p}=0.503^{\mathrm{ns}}$ \\
\hline Internet & 32 & 42 & $37.8 \%(74)$ & \\
\hline $\begin{array}{c}\text { Advertisements in magazines or } \\
\text { newspaper }\end{array}$ & 1 & 6 & $3.6 \%(7)$ & \\
\hline Television & 2 & 2 & $2 \%(4)$ & \\
\hline Word of mouth & 46 & 65 & $56.6 \%(111)$ & \\
\hline Holiday Organization Mode & & & & $\mathrm{Chi}^{2}=1.225 ; \mathrm{p}=0.268^{\mathrm{ns}}$ \\
\hline Individually & 66 & 86 & $77.6 \%(152)$ & \\
\hline Package tour & 15 & 29 & $22.4 \%(44)$ & \\
\hline Accompanying Person & & & & $\mathrm{Chi}^{2}=1.871 ; \mathrm{p}=0.600^{\mathrm{ns}}$ \\
\hline Travel alone & 12 & 19 & $15.8 \%(31)$ & \\
\hline Spouse & 19 & 21 & $20.4 \%(40)$ & \\
\hline Spouse and children & 7 & 16 & $11.7 \%(23)$ & \\
\hline Friends/relatives & 43 & 59 & $52 \%(102)$ & \\
\hline Length of Stay & & & & $\mathrm{Chi}^{2}=10.093 ; \mathrm{p}<0.05 * *$ \\
\hline One day & 8 & 3 & $5.6 \%(11)$ & \\
\hline Weekend & 18 & 44 & $31.6 \%(62)$ & \\
\hline One week & 40 & 55 & $48.5 \%(95)$ & \\
\hline More than one week & 15 & 13 & $14.3 \%(28)$ & \\
\hline $\begin{array}{c}\text { Main purpose of Barcelona visit } \\
\text { (Primary purpose) }\end{array}$ & & & & $\mathrm{Chi}^{2}=14.648 ; \mathrm{p}<0.1^{*}$ \\
\hline
\end{tabular}




\begin{tabular}{|c|c|c|c|l|}
\hline Food and cuisine & 6 & 6 & $6.1 \%(12)$ & \\
\hline Business (Conference) & 3 & 2 & $2.6 \%(5)$ & \\
\hline Visit friend/family & 14 & 11 & $12.8 \%(25)$ & \\
\hline Shopping & 6 & 5 & $5.6 \%(11)$ & \\
\hline Sightseeing & 15 & 37 & $26.5 \%(52)$ & \\
\hline Night life & 3 & 1 & $2 \%(4)$ & \\
\hline Visit historic sites & 5 & 14 & $9.7 \%(19)$ & \\
\hline Cultural experience & 17 & 31 & $24.5 \%(48)$ & \\
\hline Other & 12 & 8 & $10.2 \%(20)$ & \\
\hline
\end{tabular}

Members of cluster 2 exhibit significantly higher level of perceived authenticity, both for variable and single items. Tourists in cluster 2 perceive La Boqueria food market as authentic, as it offers authentic products, provides authentic environment and atmosphere and gives opportunity to experience local customs and culture (Table 8).

Table 8. Differences in clusters based on the Perceived authenticity

\begin{tabular}{|c|c|c|c|c|}
\hline Variable and item & $\begin{array}{c}\text { Cluster 1 (n=81) } \\
\text { Mean }\end{array}$ & $\begin{array}{c}\text { Cluster 2 (n=114) } \\
\text { Mean }\end{array}$ & \multicolumn{2}{|c|}{ Statistics } \\
\cline { 2 - 5 } & 5.15 & 5.68 & 13.066 & $* * *$ \\
\hline Perceived authenticity & 4.85 & 5.73 & 26.470 & $* * *$ \\
\hline La Boqueria offers authentic products & 4.98 & 5.83 & 27.934 & $* * *$ \\
\hline $\begin{array}{c}\text { Environment and atmosphere in La } \\
\text { Boqueria is authentic }\end{array}$ & 5.00 & 5.81 & 23.947 & $* * *$ \\
\hline $\begin{array}{c}\text { La Boqueria gives the opportunity to } \\
\text { experience local customs and culture }\end{array}$ & & & \\
\hline
\end{tabular}

Notes: $\mathrm{p}<0.001(* * * *)$

The further analysis shows that there is also difference in clusters based on the satisfaction and revisit intention. Members of cluster 2 exhibit significantly higher levels of satisfaction and revisit intention, rating agreement with almost all items within the variables at least one full point higher. Therefore, tourists of cluster 2 are more satisfied with La Boqueria food market visit and with higher likelihood to revisit La Boqueria (Table 9).

Table 9. Differences in clusters based on the Satisfaction and Revisit Intention

\begin{tabular}{|c|c|c|c|c|}
\hline \multirow{2}{*}{ Variable and item } & \multirow{2}{*}{$\begin{array}{c}\text { Cluster } 1(n=81) \\
\text { Mean }\end{array}$} & \multirow{2}{*}{$\begin{array}{c}\text { Cluster } 2(n=114) \\
\text { Mean }\end{array}$} & \multicolumn{2}{|c|}{ Statistics } \\
\hline & & & $\mathbf{F}$ & Sig. \\
\hline Satisfaction & 5.16 & 5.9739 & 48.077 & $* * *$ \\
\hline $\begin{array}{l}\text { I made the right choice visiting La } \\
\text { Boqueria }\end{array}$ & 5.17 & 5.95 & 32.715 & $* * *$ \\
\hline $\begin{array}{l}\text { Visitation of La Boqueria gave me high } \\
\text { satisfaction }\end{array}$ & 5.05 & 6.03 & 40.961 & $* * *$ \\
\hline $\begin{array}{l}\text { Visitation of La Boqueria has answered } \\
\text { my wishes }\end{array}$ & 5.27 & 5.93 & 20.685 & $* * *$ \\
\hline I am pleased to visit La Boqueria & 5.14 & 5.99 & 33.324 & $* * *$ \\
\hline & $\begin{array}{c}\text { Cluster } 1(n=81) \\
\text { Mean }\end{array}$ & $\begin{array}{c}\begin{array}{c}\text { Cluster } 2(n=114) \\
\text { Mean }\end{array} \\
\end{array}$ & & \\
\hline Revisit intention & 4.99 & 5.92 & 37.007 & $* * *$ \\
\hline I intend to revisit La Boqueria again & 5.06 & 5.87 & 24.288 & $* * *$ \\
\hline $\begin{array}{l}\text { It is very likely that I will revisit La } \\
\text { Boqueria in the future }\end{array}$ & 4.88 & 5.89 & 33.344 & $* * *$ \\
\hline $\begin{array}{c}\text { The likelihood of my return to La } \\
\text { Boqueria is high. }\end{array}$ & 5.04 & 6.00 & 34.077 & $* * *$ \\
\hline
\end{tabular}

Notes: $\mathrm{p}<0.001(* * *)$ 
Taking into account that the situation between clusters is quite different, clusters were named based on the specific characteristics dominating their cluster membership. Therefore, based on the results presented so far, clusters were labelled as:

Cluster 1, Apathetic-market visitors, consisted of 81 members (41.32\%). They are not so focused on health concern and sensory appeal of food presented in food market. Also, they are less interested in interaction with local producers and vendors and less prepared to be involved in local food experience. Regarding demographic characteristics, difference between clusters doesn't exist, but they have different travel behaviour. Apathetic visitors are usually return visitors, who are more familiar with destination, so they are staying longer, one week and more than one week. Purpose of Barcelona trip is friend and family visit or other factors. Authenticity of La Boqueria site is less important for them, and they are less satisfied with visit and with less probability to revisit food market.

Cluster 2, Food-market lovers, with a total of 114 members (58.67\%). Food market lovers have higher level of health concern, and they are more attracted by sensory appeal of food. Also they are more interested in interaction dimension, more involved with local producers and vendors, as well as in local food experience. There is no difference between clusters in their demographic characteristics, but food-market lovers have different travel patterns, as they are usually first time visitors, mainly staying for a weekend. Their purpose of Barcelona trip is determined by sightseeing and cultural experience. As cultural experience is an important determinant of travel, they perceive food market as cultural site where they can experience local culture through unique environment, but also try local gastronomy. Foodmarket lovers are more satisfied with visit and show higher level of revisit behaviour.

\section{DISCUSSION AND CONCLUSIONS}

\section{Theoretical implications}

Using a cluster analysis approach, this study examines the segmentation of tourists in one of the most famous food market in the world, La Boqueria in Barcelona, Spain. Results indicated that there were two homogenous clusters labelled as: Apathetic-market visitors and Foodmarket lovers.

Food market behaviour is proved to be an important predictor for segmenting tourists visiting food markets. The proposed segments in this paper could be helpful to understand better who is specific food market tourist and what is his/her main characteristics, so management of food market could create effective promotional campaigns and adequate business strategies.

The results of the factor analysis show that there are four dimensions of food market behaviour among tourists visiting La Boqueria: interaction with local producers and vendors, sensory appeal, health concern and local food experience. Obtained results are consistent with results in other several studies (Kim et al., 2009; Kim and Eves, 2012; Mak et al., 2013; Kim et al., 2013). Mean values of obtained factors indicate that primary importance for tourists during the food market visit is sensory appeal. These results are similar to the research by Steptoe et al. (1995), regarding motives of relevant for food selection. 
At the beginning, the clusters are observed in the context of demographic characteristics and travel behaviour. No demographic characteristics were found to be strong discriminators of group membership, confirming findings in previous studies (Kim et al., 2015; Kim et al., 2014). Nevertheless, travel behaviour variables are seen as stronger predictors than demographic characteristics (Kim, et al., 2015; Kim et al., 2014). Significant differences were apparent between clusters in terms of type of visit, length of stay and primary purpose of visit.

Differences found between Apathetic-market visitors and Food-market lovers related to type of visit is consistent with the study by Kim et al. (2010) who explore the differences between first time visitors and repeaters at a food event in the south-western part of the United States. Length of stay was also found different in cluster membership; as Apathetic-market visitors usually stay longer in destination than Food-market lovers. Length of stay was also found to be important clustering factor in other papers, mainly focused on food events (Kim, et al., 2015). At last, primary purpose of visit is one more dividing point for clusters. Therefore, sightseeing and cultural experience are the main motivators for Food-market lovers when they visit Barcelona, while Apathetic-market visitors are motivated by friends and family visit. These findings are consistent with cluster difference results between attendees of food festival held in southern states in USA (Kim et al., 2014; Kim et al., 2015).

In terms of the authenticity of La Boqueria food market perception, Food-market lovers exhibit significantly higher levels of sensed authenticity, especially for perceived environment and atmosphere. Also, Food-market lovers are not only driven by food related attributes and their behaviour as consumers, but also with cultural and architectural uniqueness of site and atmosphere experienced over there.

As noted before, satisfaction level and revisit intention was significantly different between groups. Satisfaction level is significantly higher for Food-market lovers as their perception of food market and food market behaviour are more pronounced. Sightseeing and cultural experience are main drivers for Barcelona travel, so La Boqueria as one of the top ten city tourist attractions, enables them to fulfil their expectations. Also, increased level of satisfaction is connected with the chance to experience this unique site and simultaneously perform their daily food market patterns. Interaction with local producers and vendors is one of the best ways to become more acquitted with local culture and heritage (Hjalager \& Richards, 2002). As friends and family visit is recognized as main purpose of Barcelona travel for Apathetic-market visitors, their satisfaction may depend on free and available time left for sightseeing. Food market behaviour is less manifested, so they are visiting food markets as "must see and do thing". Difference between clusters based on satisfaction level of tourists is common in food tourism literature, once again confirming our findings (Kim, et al., 2014; Kim et al., 2015).

The results also reveal that in terms of positive revisit outcome, there are statistically significant differences between these two clusters, so revisit intention of Food-market lovers is higher, as they are more satisfied with food market visits. These findings support results gained in studies conducted in food event context (Kim et al., 2015; Kim et al., 2010).

\section{Managerial implications and limitations}

Understanding who food market tourist is could help management of food markets to develop products suitable for their customers. As tourism is rapidly changing, preferences and demands of food market tourists are changing as well. Therefore, it is necessary to monitor all 
changes in food tourism praxis in order to obtain quality information about nature of their visits. As results suggest, responsible organizations for food markets development are more effective when they use marketing strategies focusing on behavioural discriminators rather than demographic variables.

As cultural authenticity and atmosphere of the food market mainly drive food-market lovers, sightseeing guided tours including local producers could be organized by market management in order to add value to their cultural experience. Interaction with local producers is also seen as important for food-market lovers, so markets management by arranging open discussions or workshops between visitors and vendors and local producers, will provide unique opportunities for producers and vendors to promote their products, while visitors will have the chance to acknowledge few interesting facts about their production.

Apathetic-market visitors have less pronounced food market behaviour, acting as ordinary tourists, perceiving food markets as "must see and do thing". This food market segmented behaviour is consisted of calm walk by the different hallways, looking the stalls and making pictures around. Some attractive proposals could imply to encourage these visitors to upload their pictures through food spotting sites securing free of charge promotion of La Boqueria. Therefore, management of the market could organize a call for best picture.

Limitation of this study may refer to travel behaviour strictly focused on Barcelona trip, so future research may expand this category to clarify the role of travel behaviour to La Boqueria. In that sense, additional information about the visit itself could be relevant to better promote the food markets amongst tourists: spent time in the market hall; number of stalls visited; used facilities; variety of bought products; money amount spent; purpose of the purchase (own consumption, as a present - mainly for non-perishable products-). Furthermore, to assess the total volume sales of the market and in particular the stalls focused on foodmarket lovers would provide more information to help the Boqueria market managers redirect its strategy, without forgetting local buyers. The authenticity of that market, as well as its attractive continuity, depends on the maintenance of the traditional stalls, the local atmosphere and the specialised and gourmet products (some of them you can just find in this market).

Future research could pursue difference between nationalities regarding their motivation and food markets patterns, so market management could prepare tailor made marketing strategy for specific origin countries based on their specific demands.

\section{REFERENCE}

Albisu, M., Gracia, A. \& Sanjuán, I. (2011), "Demographics and food con- sumption: empirical evidence", 747-769, in, Lusk J. L., J. Roosen and J. F. Shogren (dirs.), The Oxford Handbook of the Economics of Food Consumption and Policy, Oxford, Oxford University Press.

Barrado, Diego A. (2010), "Gran ciudad y turismo en la transición post-industrial: nuevos y viejos procesos, nuevas y viejas teorías. El ejemplo del Área Metropolitana de Madrid", Scripta Nova, XIV, 317, 310-322

Bolton, R. N., \& Drew, J. H. (1991), "A multistage model of customer's assessments of service quality and value". Journal of Consumer Research, 17 (4), 375-384. 
Brida, G., Disegna, M., \& Osti, L. (2013), "The effect of authenticity on tourists' expenditure at cultural events". Current Issues in Tourism, 16 (3), 266-285

Chang, T. Z., \& Wildt, A. R. (1994), "Price, product information, and purchase intention: An empirical study". Journal of the Academy of Marketing Science, 22 (1), 16-27.

Chang, R., Kivela, J. \& Mak, A. (2010), "Food preferences of Chinese Tourists", Annals of Tourism Research, 37 (4), 989-1011

Cohen, E., \& Avieli, N. (2004), "Food in tourism: Attraction and impediment". Annals of Tourism Research, 31(4), 755-778.

Crespi-Vallbona, M. \& Domínguez-Pérez, M. (2015), "Food markets: new tourism icons. Illustrative cases of Barcelona and Madrid", 127-139 in Tózsa, I. \& Zátori, A. (eds.), Metropolitan Tourism Experience Development. Department of Economic Geography and Futures Studies, Corvinus University of Budapest, Budapest.

Delfosse, C. (2011), "Heritage-making and the enhancement of so-called "terroir" products: when rural meets urban", Journal Anthropology of Food, 8, 6, 772, URL: http://aof.revues.org/6772

Everett, S., \& Aitchison, C. (2007), "Food tourism and the regeneration of regional identity in Cornwall: An exploratory case study", 167-192 in Aitchison, C. \& Pritchard, A. (eds.), Festivals and events: Culture and identity in leisure, sport and tourism. Eastbourne: Leisure Students Association.

Hair, J., Black, W., Babin, B., Anderson R., \& Tatham, R. (2006), Multivariate Data Analysis (6th ed), Upper Saddle River, NJ: Prentice Hall.

Hashimoto, A., \& Telfer, D. J. (2006), "Selling Canadian culinary tourism: Branding the global and the regional product". Tourism Geographies, 8(1), 31-55

Hjalager, A. \& Richards, G. (2002), Tourism and Gastronomy, Routledge, London

Horng, J.-S., Su, C.-S. \& So, S.-I.A. (2013), "Segmenting food festival visitors: applying the theory of planned behavior and lifestyle", Journal of Convention \& Event Tourism, Vol. 14 (3), 193-216.

Hu, Y., Banyai, M., \& Smith, S. (2013), "Expenditures, Motivations, and Food Involvement among Food Festival Visitors: The Hefei, China, Crawfish Festival", Journal of China Tourism Research, 9:4, 467-488.

Ignatov, E. \& Smith, S., (2006), "Segmenting Canadian culinary tourists". Current Issues in Tourism, 9 (3), 235-255.

Kim, Y. G., Eves, A., \& Scarles, C. (2009), "Building a model of local food consumption on trips and holidays: A grounded theory approach", International Journal of Hospitality Management, 28 (3), 423-431.

Kim, Y., Kim M., Goh, B., \& Antun, J. (2010a), "A Comparison Between First-Timers and Repeaters at a Food Event", Journal of Culinary Science \& Technology, 7:4, 239-249, DOI: 10.1080/15428050903566757

Kim, Y. G., Suh, B. W., \& Eves, A. (2010b), "The relationships between food-related personality traits, satisfaction, and loyalty among visitors attending food events and festivals". International Journal of Hospitality Management, 29 (2), 216-226.

Kim, Y., Kim, M., Goh, B., \& Antun, J. (2011a), "The role of money: The impact on food tourists' satisfaction and intention to revisit food events", Journal of Culinary Science \& Technology, 9(2), 85-98.

Kim, Y. H., Kim, M., \& Goh, B. K. (2011b), "An examination of food tourist's behavior: Using the modified theory of reasoned action". Tourism Management, 32 (5), 1159-1165.

Kim, Y. \& Eves, A. (2012), "Construction and validation of a scale to measure tourist motivation to consume local food", Tourism Management, 33, 1458-1467 
Kim, Y., Eves, A. \& Scarles, C. (2013), "Empirical verification of a conceptual model of local food consumption at a tourist destination", International Journal of Hospitality Management, 33 (0), 484-489. DOI: 10.1016/j.ijhm.2012.06.005

Kim, Y. H.,, Duncan, J., \& Jai, T.-M. (2014), "A case study of a southern food festival: using a cluster analysis approach", Anatolia: An International Journal of Tourism and Hospitality Research, 25:3, 457-473, DOI: 10.1080/13032917.2014.912245

Kim, Y. H.,, Duncan, J., \& Chung, B.W. (2015), "Involvement, Satisfaction, Perceived Value, and Revisit Intention: A Case Study of a Food Festival", Journal of Culinary Science \& Technology, 13:2, 133-158, DOI: 10.1080/15428052.2014.952482

Kivela, J. \& Crotts, J. (2006), "Tourism and gastronomy: Gastronomy's influence on how tourists experience a destination", Journal of Hospitality and Tourism Research, 30(3), 354377

Fields, K. (2002), "Demand for the gastronomy tourism product: Motivational factors", 36-50. In Hjalager, A. \& Richards, G. (Eds.), Tourism and gastronomy London: Routledge.

Lang, Mark, Stanton, John \& Qu, Yingdao (2014), "Consumers' evolving definition and expectacions for local foods", British Food Journal, Vol. 116 (11) 1808-1820

Lee, Y., Lee, C., Lee, S., \& Babin, B. (2008),"Festival scapes and patrons' emotions, satisfaction, and loyalty", Journal of Business Research, 61(1), 56-64

Lee, C., Lee, J., \& Yoon, Y. (2010), "Measuring festival quality and value affecting visitors'satisfaction and loyalty using a structural approach". International Journal of Hospitality Management, 29 (2), 335-342.

Lee, I. \& Arcodia, C. (2011), "The Role of Regional Food Festivals for Destination Branding", International Journal of Tourism Research, 13 (4), 355-367

Mak, A., Lumbers, M., Eves, A., Chang, R., (2011),"Factors influencing tourist food consumption", International Journal of Hospitality Management 31(3), 928-936

Mak, A., Lumbers, M; Eves, A. et al. (2012), "Factors influencing tourist food consumption". International Journal of Hospitality Management 31 (3), 928-936

Mak, A., Lumbers, M., Eves, A. \& Chang, R. (2013),"An Application of the Repertory Grid Method and Generalized Procrustes Analysis to Investigate the Motivational Factors of Tourist Food Consumption", International Journal of Hospitality Management, 35, 327-338

Mason, M.C. \& Paggiaro, A. (2012), "Investigating the role of festivalscape in culinary tourism: the case of food and wine events", Tourism Management, Vol. 33 (6), 1329-1336

OECD (2012), Food and the Tourism Experience. The OECD - Korea Workshop, OECD Studies on Tourism, OECD publishing

Oh, H. \& Jeong, M. (1996), "Improving marketers' predictive power of customer satisfaction on expectation based target market levels", Hospitality Research Journal 19(4), 65-85

Okumus, F., Kock, G., Scantlebury, G. \& Okumus, B. (2013), "Using local cuisines when promoting small Caribbean Island destinations", Journal of Travel and Tourism Marketing, Vol. 30 (4), 410-429

Organ, K., Koenig-Lewis, N., Palmer, A. \& Probert, J. (2015), "Festivals as agents for behaviour change: A study of food festival engagement and subsequent food choices", Tourism Management, 48, 84-99.

Park, K., Reisinger, Y., \& Kang, H. (2008), "Visitors' motivation for attending the South Beach wine and food festival, Miami Beach, Florida". Journal of Travel \& Tourism Marketing, 25 (2), 161-181.

Prescott, J., Young, O., O’Neill, L., Yau, N. \& Stevens, R. (2002), "Motives for food choice: A comparison of consumers from Japan, Taiwan, Malaysia and New Zealand", Food Quality and Preference, 13 (7), 489-495 
Richards, Greg, Wilson, Julie (2007), "Tourism development trajectories. From culture to creativity?" In Richards, G. \& Wilson, J. Tourism, Creativity and Development, London, Routledge

Robinson, R., \& Clifford, C. (2012), "Authenticity and festival foodservice experiences", Annals of Tourism Research, 39 (2), 571-600

Sanchez-Cañizares, Sandra \& Castillo-Canalejo, Ana M, (2015), "A comparative study of tourist attitudes towards culinary tourism in Spain and Slovenia", British Food Journal, Vol. 117 (9), 2387-2411

Sims, R. (2009), "Food, place and authenticity: local food and the sustainable tourism experience". Journal of Sustainable Tourism, 17(3), 321-336

Smith, S. \& Xiao, H. (2008). "Culinary tourism supply chains: a preliminary examination". Journal of Travel Research, 46 (3), 289-299

Steptoe, A., Pollard, T. \& Wardle, J. (1995), "Development of a measure of the motives underlying the selection of food: the Food Choice Questionnaire". Appetite, 25 (3), 267-284

Swenson, D, (2009), Investigating the potential economic impacts of local foods for southeast Iowa. Iowa State University. Department of Economics.

Sonmez, S. \& Graefe, R. (1998), "Determining future travel behavior from past travel experience and perceptions of risk and safety". Journal of Travel Research, 37 (2), 171-177.

Taylor, J. (2001), "Authenticity and sincerity in tourism", Annals of Tourism Research, 28 (1), 7-26

Tregear, A., Kuznesof, S. \& Moxey, A. (1998), "Policy initiatives for regional foods: some insights from consumer research", Food Policy, Vol. 23 (5), 383-94

Tse, P. \& Crotts, J.C. (2005), "Antecedents of novelty seeking: international visitors' propensity to experiment across Hong Kong's culinary traditions". Tourism Management, 26 (6), 965-968.

Turner, B., \& Hope, C. (2014), "Ecological connections: Reimagining the role of farmers' markets", Rural Society, 23:2, 175-187

Wan, Y. \& Chan, S. (2013), "Factors that affect the levels of tourists' satisfaction and loyalty towards food festivals: A case study of Macau", International Journal of Tourism Research, 15(6), 226-240.

Yuan, J., Cai, L. A., Morrison, A. M., \& Linton, S. (2005), "Segmenting wine festival attendees: A factor-cluster approach". Tourism Review International, 8 (4), 297-309.

Yuan, J. J. and Jang, S.S., 2008, "The effects of quality and satisfaction on awareness and behavioral intentions: exploring the role of a wine festival". Journal of Travel Research 46 (3): 279-288

Yuksel, A. \& Yuksel, F. (2002a), "Market segmentation based on tourists' dining preferences", Journal of Hospitality \& Tourism Research, 26 (4), 315-331

Yuksel, A. \& Yuksel, F. (2002b), "Measurement of tourist satisfaction with restaurant services: A segment based approach", Journal of Vacation Marketing, 9 (1), 52-68

Zanoli, R. \& Naspetti, S. (2002), "Consumer motivations in the purchase of organic food. A means-end Approach", British Food Journal, 104 (8), 643-653

Zeithaml, V. A. (1988), "Consumer perceptions of price, quality and value: A means-end model and synthesis of evidence". Journal of Marketing, 52 (3), 2-22. 